DE

M E D I C I N A

T R O P I C A L

$\mathrm{DE}$

SÃO PAULO

JOURNAL OF THE SÃO PAULO INSTITUTE OF TROPICAL MEDICINE

(1) Fundação Oswaldo Cruz (Fiocruz/PE), Centro de Pesquisas Aggeu Magalhães, Laboratório de Biologia Celular e Molecular, Recife, Pernambuco, Brazil.

(2) Universidade Federal de Pernambuco, Laboratório de Planejamento e Síntese de Fármacos (LPSF), Departamento de Antibióticos, Recife, Pernambuco, Brazil.

(3) Universidade Federal de Pernambuco, Laboratório de Imunopatologia Keizo Asami, Recife, Pernambuco, Brazil

(4) Universidade Federal de Pernambuco, Laboratório de Imunomodulação e Novas Abordagens Terapêuticas, Núcleo de Pesquisas em Inovação Terapêutica Suely Galdino, Recife, Pernambuco, Brazil

Correspondence to: Thiago José MatosRocha.

Universidade Federal de Pernambuco, Laboratório de Imunomodulação e Novas Abordagens Terapêuticas, Núcleo de Pesquisas em Inovação Terapêutica Suely Galdino. Rua Thereza Amélia s/n, Cidade Universitária, CEP 50670-901, Recife, PE, Brazil.

E-mail: thy_rocha@ hotmail.com

Received: 27 March 2015

Accepted: 22 September 2016

\section{Synthesis and biological evaluation of novel imidazolidine derivatives as candidates to schistosomicidal agents}

\author{
Thiago José Matos-Rocha ${ }^{1,3,4}$, Maria do Carmo Alves de Lima², Anekécia \\ Lauro da Silva ${ }^{2}$, Jamerson Ferreira de Oliveira ${ }^{2}$, Allana Lemos Andrade

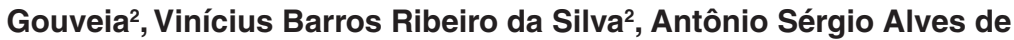 \\ Almeida Júnior², Fábio André Brayner ${ }^{1,3}$, Pablo Ramon Gualberto Cardoso4, \\ Marina da Rocha Pitta-Galdino², Ivan da Rocha Pitta², Moacyr Jesus Barreto \\ de Melo Rêgo ${ }^{4}$, Luiz Carlos Alves ${ }^{1,3}$, Maira Galdino da Rocha Pitta ${ }^{4}$
}

\section{ABSTRACT}

Introduction: Schistosomiasis is an infectious parasitic disease caused by trematodes of the genus Schistosoma, which threatens at least 258 million people worldwide and its control is dependent on a single drug, praziquantel. The aim of this study was to evaluate the anti-Schistosoma mansoni activity in vitro of novel imidazolidine derivatives. Material and methods: We synthesized two novel imidazolidine derivatives: (LPSF/PTS10) (Z)-1(2-chloro-6-fluorobenzyl)-4-(4-dimethylaminobenzylidene)-5-thioxoimidazolidin-2-one and (LPSF/PTS23) (Z)-1-(2-chloro-6-fluoro-benzyl)-5-thioxo-4-(2,4,6-trimethoxy-benzylidene)imidazolidin-2-one. The structures of two compounds were determined by spectroscopic methods. During the biological assays, parameters such as motility, oviposition, mortality and analysis by Scanning Electron Microscopy were performed. Results: LPSF/PTS10 and LPSF/PTS23 were considered to be active in the separation of coupled pairs, mortality and to decrease the motor activity. In addition, LPSF/PTS23 induced ultrastructural alterations in worms, after $24 \mathrm{~h}$ of contact, causing extensive erosion over the entire body of the worms. Conclusion: The imidazolidine derivatives containing the trimetoxy and benzylidene halogens showed promising in vitro schistosomicidal activity.

KEYWORDS: Schistosoma mansoni. Imidazolidines. Ultrastructure.

\section{INTRODUCTION}

Parasitic diseases remain obstacles to socioeconomic development in poor countries. Schistosomiasis ${ }^{1}$, an infection caused by trematode worms of the genus Schistosoma, is the second most significant parasitic disease in the world after malaria. It is a chronic and debilitating disease that continues to threaten millions of people, particularly in the rural poor areas of the developing world ${ }^{2}$.

The major etiological agent of intestinal schistosomiasis is Schistosoma mansoni, and it is estimated that up to 258 million people are infected ${ }^{3}$.

The reference drug for the treatment of schistosomiasis is praziquantel (PZQ) (2-cyclohexylcarbonyl-1,2,3,6,7,11b-hexa-hydro- $4 H$-pyrazino $\{2,1-\mathrm{a}\}$ isoquinoline4-one $)^{4}$. Recent reports of resistance in some strains raised concern to the world's public health organizations ${ }^{5}$. In this context, the identification of new and effective schistosomicidal compounds is essential ${ }^{6}$.

At present, various research groups are dedicating efforts to identifying new 
schistosomicidal agents obtained from natural ${ }^{7,8}$ and synthetic sources $^{9,10}$. The importance of heterocyclic compounds as potential agents against several parasitic diseases, caused by protozoa and helminths, is well known ${ }^{11}$.

The imidazolidines are a broad class of bioactive compounds that have also schistosomicidal properties. Niridazole, 1-(5-nitrothiazol-2yl) imidazolidin-2-one, a drug used during the last century, has been widely applied in clinical practice ${ }^{12}$ and was one of the early treatment options to be administered orally ${ }^{13}$.

Imidazolidines have antifungal, antimicrobial and leishmanicidal ${ }^{14}$, anti-Trypanosoma cruzi $^{15}$ and schistosomicidal properties ${ }^{16,17}$. The latter activity of imidazolidine derivatives has been demonstrated by in vitro studies with adult $S$. mansoni worms. However, as for PZQ, the mechanism of action of the imidazolidines has not yet been fully elucidated ${ }^{18,19}$.

The molecular modification of imidazolidines by bioisosteric replacement produces a biological response. This study evaluated the biological activity of imidazolidine derivatives with different substituent groups by determining their in vitro activity against adult worms of $S$. mansoni $i^{16-19}$.

Two novel imidazolidine compounds (LPSF/ PTS10) (Z)-1-(2-chloro-6-fluorobenzyl)-4-(4-dimethyl aminobenzylidene)-5-thioxoimidazolidin-2-one and (LPSF/ PTS23) (Z)-1-(2-chloro-6-fluorobenzyl)-5-thioxo-4-(2,4,6trimethoxybenzylidene) imidazolidin-2-one, were tested by an in vitro activity evaluation and an ultrastructural analysis of the parasite, and by evaluating the cytotoxicity of the tested compound on PBMCs.

\section{MATERIALS AND METHODS}

\section{Compounds}

The compounds (LPSF/PTS10)-(Z)-1-(2-chloro6-fluorobenzyl)-4-(4-dimethyl aminobenzylidene)5-thioxoimidazolidin-2-one and (LPSF/PTS23)(Z)-1-(2-chloro-6-fluorobenzyl)-5-thioxo-4-(2,4,6trimethoxybenzylidene) imidazolidin-2-one were obtained from Laboratório de Planejamento e Síntese de Fármacos at Universidade Federal de Pernambuco (Brazil) and their identities verified by ${ }^{1} \mathrm{H}$ nuclear magnetic resonance of hydrogen ( ${ }^{1} \mathrm{H}$ NMR), infrared (IR) and mass spectroscopy (MS).

Scheme 1 displays the synthetic route of the three derivatives. The starting reagent was imidazolidine-2,4dione (1) which was reacted with 2-chloro-6-fluorobenzyl chloride under basic conditions to obtain the intermediate 3-(2-chloro-6-fluorobenzyl) imidazolidine-2,4-dione as previously described (2) ${ }^{20}$. After that, the reaction of 3-(2-chloro-6-fluorobenzyl) imidazolidine-2,4-dione (2) with Lawesson's reagent in anhydrous dioxane gave the compound 1-(2-chloro-6-fluorobenzyl)-5thioxoimidazolidin-2-one (3) according to the protocol used by Gouveia et al. ${ }^{21}$. The reaction mixture was heated under reflux for 24 hours. Confirmation of the reaction was accomplished by mass spectrometry when it was shown that the compound $2 \mathrm{~m} / z(M+\mathrm{H})^{+}$ $=243.035$ became the compound $3 \mathrm{~m} / z(M+\mathrm{H})^{+}=$ 259.013 by changing the oxygen atom in the sulfur in the structure. Then 2-cyano-3-phenyl-acrylic acid ethyl esters derivatives were synthesized through Knoevenagel condensation between 4-dimethylaminobenzaldehyde or 2,4,6-trimethoxybenzaldehyde and ethyl cyanoacetate . $^{8}$ A Michael-type addition was then performed by reacting the ester derivatives with the intermediate 1-(2-chloro-6fluorobenzyl)-5-thioxoimidazolidin-2-one (3) to form the final compounds (LPSF/PTS10 and LPSF/PTS23).

Reactions were monitored with analytical thinlayer chromatography in silica gel 60 F254 plates and visualized under UV light $(254 \mathrm{~nm})$. Melting points were determined on a Quimis 340 capillary melting point apparatus and were not corrected. Infrared spectra were recorded as $\mathrm{KBr}$ discs using a BRUKER (IFS66) infrared spectrophotometer. ${ }^{1} \mathrm{H}$ NMR spectra were recorded in a VMMRS $300 \mathrm{MHz}$ and $400 \mathrm{MHz}$ VARIAN spectrometer using tetramethylsilane (TMS) as the internal standard and DMSO- $d_{6}$ as the solvent.

Chemical shifts $(\delta, \mathrm{ppm})$ were assigned according to the internal standard signal of TMS in DMSO- $d_{6}$ $(\delta, \mathrm{ppm})$. Coupling constants $(J)$ are reported in $\mathrm{Hz}$. ${ }^{1} \mathrm{H}$ NMR spectra are reported in the following order: chemical shift, multiplicity, number and type of proton and coupling constant(s). Mass spectra with MALDI-TOF Autoflex III (Bruker Daltonics, Billerica, MA, USA). Laser Nd: YAG, 355 nm. Freq. laser: $100 \mathrm{~Hz}$. The derivatives (LPSF/PTS10; LPSF/PTS23) were isolated as a single isomer. X-ray crystallographic studies and ${ }^{13} \mathrm{C}$ NMR have shown a preferred $Z$ configuration for 5-benzylidenethiazolidinones ${ }^{22-25}$.

The presence of the arylidene proton peak in ${ }^{1} \mathrm{H}$ NMR for the synthesized derivatives (LPSF/PTS10; LPSF/PTS23) confirmed the completion of the nucleophilic addition reaction. The compounds were also confirmed by MS data in negative mode.

The IR spectrum of the compound showed characteristic peaks of the thiocarbonyl group and arylidene, confirming the formation of 5-thioxoimidazolidin-2-one derivatives. For the preparation of compounds, equimolar amounts of 1-(2-chloro-6-fluorobenzyl)-5-thioxoimidazolidin-2-one 


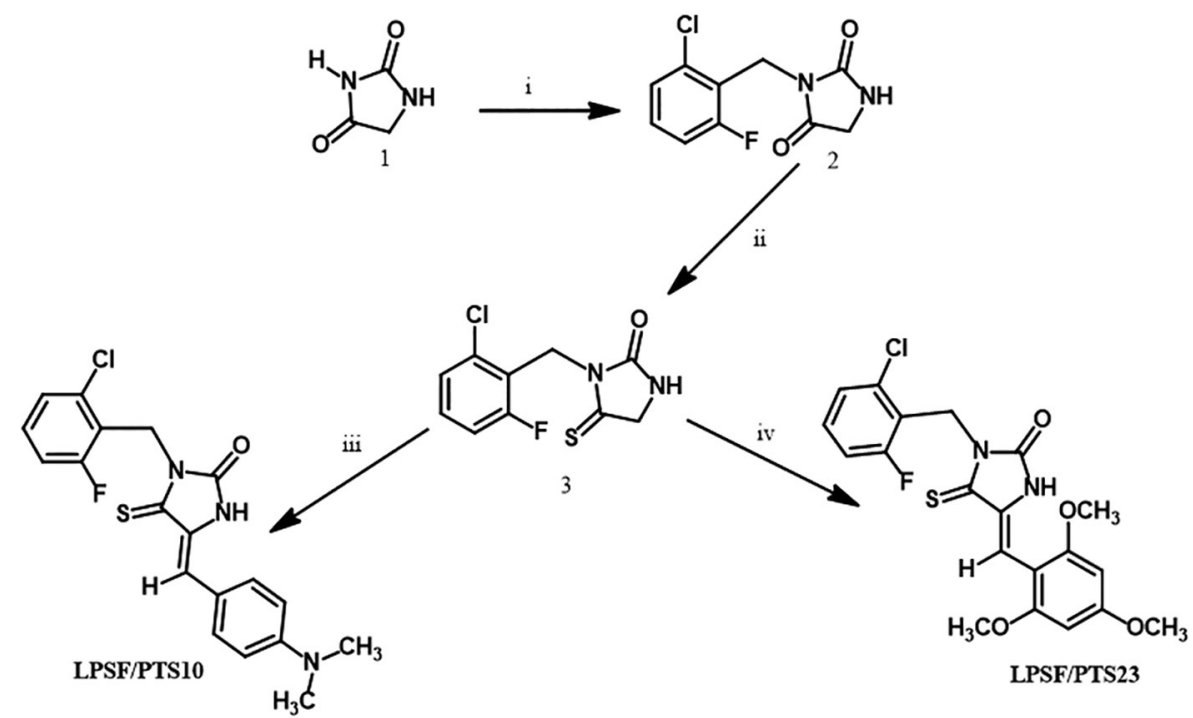

Scheme 1 - Reagents and conditions: (i) 2-chloro-6-fluorobenzyl chloride; $\mathrm{CH}_{3} \mathrm{OH}, \mathrm{NaOH}, 60^{\circ} \mathrm{C}$ (ii) Lawesson's reagent, $90 \stackrel{\circ}{ } \mathrm{C}$ (iii) 2-cyano-3-(4-dimethylaminephenyl)acrylic acid ethyl ester, $\mathrm{CH}_{3} \mathrm{CH}_{2} \mathrm{OH}, 50 \stackrel{\circ}{\circ} \mathrm{C}$; (iv) 2-cyano-3-(2,4,6-trimethoxy-phenyl)acrylic acid ethyl ester, $\mathrm{CH}_{3} \mathrm{CH}_{2} \mathrm{OH}, 50 \stackrel{\circ}{\mathrm{C}}$.

(3) (200mg) and 2-cyano-3-phenylacrylic acid ethyl ester $(165 \mathrm{mg})$ were reacted using absolute ethanol $(8 \mathrm{~mL})$ as the solvent and morpholine $(1 \mathrm{~mL})$ as the catalyst.

The reaction mixture was heated to $50^{\circ} \mathrm{C}$ for 8 hours and then cooled to room temperature. The solid that precipitated out was filtered under vacuum and washed with water and absolute ethanol.

\section{Determination of cytotoxicity}

Peripheral blood mononuclear cells were obtained from heparinized blood from healthy, nonsmoking donors who had not taken any medication for at least 15 days prior to the sample collection (10 volunteers), and cells were isolated via a standard method of density-gradient centrifugation using a Ficoll Hypaque solution (GE Healthcare). Cells were counted in a Neubauer chamber, and viability was determined by the trypan blue exclusion method. Cells were used only when the viability was at last $98 \%$. All the donors gave informed consent, and the study was approved by the Human Research Ethics Committee of UFPE in the Health Sciences Center (CEP/CCS/UFPE N0 483/10 and 57/10). Cells were plated in 96 -well plates $\left(10^{6}\right.$ cells/well $)$. After $24 \mathrm{~h}$, the test compound was added $(1,10$ and $100 \mu \mathrm{M})$ in triplicate wells, the cells were incubated for $48 \mathrm{~h}$ and then subjected to the MTT assay.

Cytotoxicity was quantified by the ability of living cells to reduce the tetrazolium dye MTT to formazan, a purple compound. Measurements were performed by using enzyme-linked immunosorbent assay (ELISA) kits (eBiosciences, USA, and BD Biosciences, USA) according to the manufacturers' instructions. At the end of the incubation period, wells were centrifuged, and the medium was replaced by $150 \mu \mathrm{L}$ of another medium without the compound containing MTT $(0.5 \mathrm{mg} / \mathrm{mL})$. Three hours later the MTT formazan was diluted with $100 \mu \mathrm{L}$ of $20 \%$ SDS, and its absorbance was measured at $570 \mathrm{~nm}$ in a BioTek EL808 reader. Cytotoxic activity was quantified as the percentage of reduction in absorbance relative to a vehicle treated control. In all the analyzed experiments, the vehicle (DMSO $0.1 \%$ ) treated group presented $>98 \%$ of viability compared to the control cells without vehicle in three independent assays ${ }^{26}$.

\section{Anti-schistosomal evaluation criteria}

\section{Parasites}

S. mansoni (LE strain) worms were maintained in Biomphalaria glabrata snails and Swiss webster mice hosts at the Schistosomiasis Laboratory of the Department of Parasitology, Oswaldo Cruz Foundation, (Pernambuco, Brazil). Female mice weighing 28-30g were each exposed to around 120 cercariae.

\section{Mice infection}

Mice were infected by the tail immersion method. Briefly, mice were individually placed in a mouseholding chamber with their tails outside the chambers. After cleaning with dechlorinated tap water, the tail was inserted into a vial containing 120 cercariae in $2 \mathrm{~mL}$ of dechlorinated tap water. Mice were left in contact with the infective cercariae for $2 \mathrm{~h}$, and then removed from the chamber, and their tails were allowed to dry. After 8 weeks, adults $S$. mansoni worms were recovered from the mice 
by perfusion with RPMI 1640 medium supplemented with heparin. The worms were washed in RPMI 1640 medium (Gibco) supplemented with $100 \mu \mathrm{g} . \mathrm{mL}^{-1}$ of streptomycin,

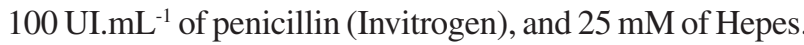
Two pairs of adult worms (male and female) were incubated in a 24-well culture plate (Techno Plastic Products, TPP) containing $2 \mathrm{~mL}$ of the same medium supplemented with $10 \%$ heat-inactivated calf serum at $37{ }^{\circ} \mathrm{C}$ in a $5 \% \mathrm{CO}_{2}$ atmosphere, in three independent assays ${ }^{27}$.

\section{In vitro viability and motility assay with $S$. mansoni}

For the in vitro test with $S$. mansoni, LPSF/PTS10 and LPSF/PTS23 imidazolidine derivatives were the compounds rather dissolved in DMSO and the final concentration of DMSO in the culture medium was a maximum of $1.6 \%$ DMSO and used in concentrations varying from 5 to $100 \mu \mathrm{M}$, which were added to the medium containing the worms after a period of $2 \mathrm{~h}$ of adaptation to the culture medium. In the positive control group, the adult worms of $S$. mansoni were incubated in the presence of PZQ, triplicates were carried out for each concentration used.

An inverted microscope and a stereomicroscope were used to evaluate the motility and survival of worms monitored at 24, 48, 72, 96 and $120 \mathrm{~h}$ of incubation. Motility and survival of worms were assessed according to the criteria scored in a viability scale of 0-3. The scoring system was as follows: 3 - complete body movement; 1.5 partial body movement or immobile but alive; and 0 - dead, at least three independent assays ${ }^{28}$. Changes in the pairing and egg production were also evaluated using an inverted microscope.

The parasites were kept for 5 days and monitored every $24 \mathrm{~h}$ to evaluate their general condition: motor activity, alterations in the tegument, and mortality rate. The control worms were treated with 1.6\% DMSO in an RPMI 1640 medium $^{29}$

\section{Scanning Electron Microscopy (SEM)}

The worms were incubated for $24 \mathrm{~h}$ and, after their death, they were washed with sodium cacodylate buffer $(\mathrm{pH}=7.2)$, fixed with $2.5 \%$ glutaraldehyde $(\mathrm{pH}=7.4)$ during $24 \mathrm{~h}$, and then fixed with $1 \%$ osmium tetroxide for $1 \mathrm{~h}$. The samples were dehydrated by an increasing amount of ethanol solution, dried in a critical point dryer, then mounted on stubs and coated with gold using a sputter coater. The material was examined under a JEOL - 5600 LV microscope.

\section{RESULTS}

\section{Compound}

(Z) - 1 - ( 2 - chloro - 6 - fl uorobenzy ) - 4 - ( 4 (dimethylaminobenzylidene)-5-thioxo imidazolidin-2one (LPSF/PTS10): The product was an orange solid. Formula: $\mathrm{C}_{19} \mathrm{H}_{17} \mathrm{ClFN}_{3} \mathrm{OS}$; M.W.: $389.8742 \mathrm{~g} / \mathrm{moles}$; Yield: $45 \%$; Melting point: $269-270{ }^{\circ} \mathrm{C} ; \mathrm{R}_{f} \cdot 0.55$ ( $n$-hexane/ AcOEt 6:4); ${ }^{1} \mathrm{H}$ NMR (300MHz, DMSO- $d_{6}$ ): $\delta 3.00$ (s, 6H, $\left.\mathrm{H}_{3} \mathrm{C}-\mathrm{N}\right) ; 5.15$ (s, 2H, $\mathrm{CH}_{2}$ ); 6.72 (d, 2H, H-Ar, J= 9.2 Hz); 7.57 (d, 2H, H-Ar, J= 8.8 Hz); 6.95 (s, 1H, HC=); 7.33 (m, 2H, CH-Ar, benzyl); 7.17 (t, 1H, CH-Ar, benzyl, J= 8.8 $\mathrm{Hz}) ; 11.00$ (s, 1H, NH). IR ( $\left.\mathrm{KBr}, \mathrm{cm}^{-1}\right)$ : 3226.68; 1725.22; 1588.95; 1531.52. $\mathrm{MS}[\mathrm{M}+\mathrm{H}]^{+}:$calculated $=390.07$; found $=$ 390.00 .

(Z)-1-(2-chloro-6-fluorobenzyl)-5-thioxo-4-(2,4,6trimethoxybenzylidene) imidazolidin-2-one (LPSF/ PTS23): The product was an orange solid. Formula: $\mathrm{C}_{20} \mathrm{H}_{18} \mathrm{ClFN}_{2} \mathrm{O}_{4} \mathrm{~S}$; M.W.: $436.8843 \mathrm{~g} / \mathrm{moles}$; Yield: 55\%; Melting point: $152-153^{\circ} \mathrm{C} ; \mathrm{R}_{f} 0.40$ ( $n$-hexane/AcOEt 6:4); ${ }^{1} \mathrm{H}$ NMR $\left(300 \mathrm{MHz}, \mathrm{DMSO}-d_{6}\right): \delta 3.809\left(\mathrm{~s}, 6 \mathrm{H}, \mathrm{OCH}_{3}\right)$; $3.83\left(\mathrm{~s}, 3 \mathrm{H}, \mathrm{OCH}_{3}\right) ; 5.13\left(\mathrm{~s}, 2 \mathrm{H}, \mathrm{CH}_{2}\right) ; 6.26(\mathrm{~s}, 2 \mathrm{H}, \mathrm{CH}-$ $\mathrm{Ar}) ; 6.99$ (s, 1H, CH=); 7.18 (t, 1H,CH-benzyl, J= 8.1 Hz); 7.34 (m, 2H, CH- benzyl); 10.08 (s, 1H, NH). IR (KBr, $\left.\mathrm{cm}^{-1}\right): 3413.59 ; 1747.92 ; 1598.88 ; 1510.63$. MS $[\mathrm{M}+\mathrm{H}]^{+}$: calculated $=437.06$; found $=437.00$.

\section{Schistosomicidal activity}

Imidazolidine composites have previously shown action against $S$. mansoni adult worms ${ }^{30-32}$.

Initially, we performed cell viability tests with the newly synthesized imidazolidine derivatives using peripheral blood mononuclear cells (PBMCs). Our results show that compounds LPSF/PTS10 and LPSF/PTS23, present no toxic effects at different concentrations ranging from 5-100 $\mu \mathrm{M}$ (Table 1).

These compounds were then evaluated for their effects on adult schistosomes at a concentration of 5 to $100 \mu \mathrm{M}$ every $24 \mathrm{~h}$ for a period of $120 \mathrm{~h}$, and mortality, motility, and alterations in the tegument of the worms were observed (Table 1). PZQ was used as the reference schistosomicidal drug.

In order to evaluate the pairing and egg production by adult worms of $S$. mansoni, the LPSF/PTS10 and LPSF/ PTS23 were tested at concentrations which cause separation of coupled adult worms and inhibition in the egg production after $120 \mathrm{~h}$ of incubation.

LPSF/PTS10 and LPSF/PTS23 all demonstrated 
Table 1 - Cytotoxicity and in vitro effects of LPSF/PTS10 and LPSF/PTS23 against adult worms of Schistosoma mansoni.

\begin{tabular}{|c|c|c|c|c|c|c|c|}
\hline \multirow{3}{*}{ Groups } & \multirow{3}{*}{ Time $(h)$} & \multicolumn{4}{|c|}{ Concentration $(\mu \mathrm{M})$} & \multirow{3}{*}{ Remarks (worms) } & \multirow{3}{*}{ Cytotoxicity $(\mu \mathrm{M})^{2}$} \\
\hline & & 100 & 40 & 20 & 5 & & \\
\hline & & \multicolumn{4}{|c|}{ Mortality (\%) } & & \\
\hline \multirow{5}{*}{ RPMI 1640} & 24 & - & - & - & - & \multirow{5}{*}{$\begin{array}{l}\text { Paired worms without apparent morphological } \\
\text { change, presence of eggs. }\end{array}$} & \multirow{5}{*}{ al } \\
\hline & 48 & - & - & - & - & & \\
\hline & 72 & - & - & - & - & & \\
\hline & 96 & - & - & - & - & & \\
\hline & 120 & - & - & - & - & & \\
\hline \multirow{5}{*}{ DMSO 1.6\% } & 24 & - & - & - & - & \multirow{5}{*}{$\begin{array}{l}\text { Paired worms without apparent morphological } \\
\text { change, presence of eggs. }\end{array}$} & \multirow{5}{*}{-} \\
\hline & 48 & - & - & - & - & & \\
\hline & 72 & - & - & - & - & & \\
\hline & 96 & - & - & - & - & & \\
\hline & 120 & - & - & - & - & & \\
\hline \multirow{5}{*}{ PZQ } & 24 & 100 & 100 & 100 & 100 & \multirow{5}{*}{$\begin{array}{l}\text { Not paired, no sucker adherence, absence of } \\
\text { eggs, tegument morphology altered }\end{array}$} & \multirow{5}{*}{$>100$} \\
\hline & 48 & 100 & 100 & 100 & 100 & & \\
\hline & 72 & 100 & 100 & 100 & 100 & & \\
\hline & 96 & 100 & 100 & 100 & 100 & & \\
\hline & 120 & 100 & 100 & 100 & 100 & & \\
\hline \multirow{5}{*}{ LPSF/PTS10 } & 24 & 100 & - & - & - & \multirow{5}{*}{$\begin{array}{l}\text { Unpaired, no sucker adherence, absence of } \\
\text { eggs, tegument morphology altered }\end{array}$} & \multirow{5}{*}{$>100$} \\
\hline & 48 & 100 & 100 & - & - & & \\
\hline & 72 & 100 & 100 & 100 & - & & \\
\hline & 96 & 100 & 100 & 100 & - & & \\
\hline & 120 & 100 & 100 & 100 & - & & \\
\hline \multirow{5}{*}{ LPSF/PTS23 } & 24 & 100 & 100 & 100 & - & \multirow{5}{*}{$\begin{array}{l}\text { Unpaired, no sucker adherence, absence of } \\
\text { eggs, tegument morphology altered }\end{array}$} & \multirow{5}{*}{$>100$} \\
\hline & 48 & 100 & 100 & 100 & - & & \\
\hline & 72 & 100 & 100 & 100 & - & & \\
\hline & 96 & 100 & 100 & 100 & - & & \\
\hline & 120 & 100 & 100 & 100 & 25 & & \\
\hline
\end{tabular}

${ }^{\mathrm{a} C a l c u l a t e d}$ at three concentrations using data obtained from at least three independent experiments, with a SD less than $10 \%$ in all cases. The highest nontoxic concentration on PBMCs.

lethality against adult worms of S. mansoni, whereas no mortality was observed for worms incubated in medium alone or in the presence of DMSO. LPSF/PTS10 was more effective, causing $100 \%$ mortality after $72 \mathrm{~h}$ at $20 \mu \mathrm{M}$. The most effective compound was LPSF/PTS23, which caused $100 \%$ mortality after $24 \mathrm{~h}$ at a concentration of $20 \mu \mathrm{M}$, and some mortality at $5 \mu \mathrm{M}$ after $120 \mathrm{~h}$ incubation.

In these experiments PZQ induced $100 \%$ mortality of adult worms after $24 \mathrm{~h}$ of incubation at all concentrations used, down to $5 \mu \mathrm{M}$.

Analysis of the effects of the compounds on worm motility allowed the detection of their action at sub-lethal concentrations (Table 2). During the complete observation period (up to $120 \mathrm{~h}$ ) the negative control group displayed peristaltic movements and characteristic waves throughout the whole body, with suckers in constant movement and occasionally adhering to the bottom of the culture plate $($ score $=3)$. PZQ caused loss of motility in worms at all concentrations used, as early as $24 \mathrm{~h}$ after the beginning of the incubation leaving them shortened. This effect persisted and became stronger over time (score $=0$ ).

After $24 \mathrm{~h}$ of exposure to LPSF/PTS23 and $48 \mathrm{~h}$ to LPSF/PTS10 at a concentration of $100 \mu \mathrm{M}, 100 \%$ of the worms had lost the movements completely, therefore being considered dead (score $=0$ ).

LPSF/PTS 10 at the concentration of $5 \mu \mathrm{M}$, did not alter the motility of $S$. mansoni during the observation period. However, a reduced motility was observed for $50 \%$ of worms after $24 \mathrm{~h}$ of incubation at $20 \mu \mathrm{M}$, and $75 \%$ were dead after $48 \mathrm{~h}$ of incubation at this concentration. In the case of LPSF/PTS23, its effects on the worms were far more radical, and it was therefore not possible to detect 
Table 2 - Motility control scores, and worms treated with the derivatives LPSF/PTS10 and LPSF/PTS23, as well as praziquantel (PZQ) at different hours post-incubation.

\begin{tabular}{|c|c|c|c|c|c|c|c|c|c|c|c|c|c|c|c|c|}
\hline \multirow{3}{*}{ Groups } & \multirow{3}{*}{$\begin{array}{c}\text { Number of } \\
\text { worms }\end{array}$} & \multicolumn{15}{|c|}{ Percentage of worms (\%) with respect to motility scores after incubation ${ }^{a}$} \\
\hline & & \multicolumn{3}{|c|}{$24 \mathrm{~h}$} & \multicolumn{3}{|c|}{$48 \mathrm{~h}$} & \multicolumn{3}{|c|}{$72 \mathrm{~h}$} & \multicolumn{3}{|c|}{$96 \mathrm{~h}$} & \multicolumn{3}{|c|}{$120 \mathrm{~h}$} \\
\hline & & 3.0 & 1.5 & 0 & 3.0 & 1.5 & 0 & 3.0 & 1.5 & 0 & 3.0 & 1.5 & 0 & 3.0 & 1.5 & 0 \\
\hline RPMI 1640 & & 100 & & & 100 & & & 100 & & & 100 & & & 100 & & \\
\hline DMSO $1.6 \%$ & & 100 & & & 100 & & & 100 & & & 100 & & & 100 & & \\
\hline \multicolumn{17}{|l|}{$P Z Q$} \\
\hline $5 \mu \mathrm{M}$ & 12 & & & 100 & & & 100 & & & 100 & & & 100 & & & 100 \\
\hline $20 \mu \mathrm{M}$ & 12 & & & 100 & & & 100 & & & 100 & & & 100 & & & 100 \\
\hline $40 \mu \mathrm{M}$ & 12 & & & 100 & & & 100 & & & 100 & & & 100 & & & 100 \\
\hline $100 \mu \mathrm{M}$ & 12 & & & 100 & & & 100 & & & 100 & & & 100 & & & 100 \\
\hline \multicolumn{17}{|l|}{ LPSF/PTS10 } \\
\hline $5 \mu \mathrm{M}$ & 12 & 100 & & & 100 & & & 100 & & & 100 & & & 100 & & \\
\hline $20 \mu \mathrm{M}$ & 12 & 50 & 50 & & & 25 & 75 & & & 100 & & & 100 & & & 100 \\
\hline $40 \mu \mathrm{M}$ & 12 & 25 & 75 & & & & 100 & & 75 & 25 & & & 100 & & & 100 \\
\hline $100 \mu \mathrm{M}$ & 12 & & & 100 & & & 100 & & & 100 & & & 100 & & & 100 \\
\hline \multicolumn{17}{|l|}{ LPSF/PTS23 } \\
\hline $5 \mu \mathrm{M}$ & 12 & 100 & & & 100 & & & 100 & & & 100 & & & 25 & 50 & 25 \\
\hline $20 \mu \mathrm{M}$ & 12 & & & 100 & & & 100 & & & 100 & & & 100 & & & 100 \\
\hline $40 \mu \mathrm{M}$ & 12 & & & 100 & & & 100 & & & 100 & & & 100 & & & 100 \\
\hline $100 \mu \mathrm{M}$ & 12 & & & 100 & & & 100 & & & 100 & & & 100 & & & 100 \\
\hline
\end{tabular}

aThe measurement of the mean worm motility was recorded on a scale from 0 to 3 , as follows: 3 , movement of the whole body; 1.5 , movement of only one part of the body or immobile but not dead; 0 , dead.

early effects on motility at the drug concentrations used. At $5 \mu \mathrm{M}$ this compound caused a reduction in motility (score 1.5 ) in $50 \%$ of the worms and $25 \%$ were dead.

Observations of worm morphology using SEM showed that in the controls, the parasite tegument was observed with oral and ventral suckers, and tubercles and spines in normal state at $120 \mathrm{~h}$ of incubation, (Fig. 1A-B). Severe damage of the tegument was observed in worms incubated with PZQ, characterized by a contraction and rupture of blisters. The emergence of several holes where the blisters had been located, and loss of spines has also been observed (Fig. 1C).

The ultrastructural changes in adult schistosomes caused by LPSF/PTS23 were characterized by extensive erosion over the entire body of the worms (Fig. 1D); after $48 \mathrm{~h}$, multiple bubbles and projections (arrows) emerging from the interior of damaged tubercles (Fig. 1E); after $72 \mathrm{~h}$, tegument erosion can be visualized at a higher magnification (Fig. 1F); After 96 h, some tubercles lack their spines (arrow) (Fig. 1G).

\section{DISCUSSION}

Schistosomiasis is a neglected disease that has only one drug of choice, PZQ. Because of this, the Special Program for Research and Training in Tropical Diseases promoted by WHO provides opportunities for studies in the development of new anti-Schistosoma drugs and encourages worldwide synthesis of new compounds for these neglected disease ${ }^{33-35}$.

Imidazolidine derivatives have previously been investigated for their anti-parasitic activity ${ }^{16-19}$. The main activities assigned to imidazolidines are antibacterial and anti-L. amazonensis ${ }^{14}$, anti-T. cruzi $i^{13}$ and anti-S. mansoni $i^{16-19}$. Among the various schistosomicidal compounds that have been already tested, imidazolidine derivatives have in vitro and in vivo efficacy in several studies, resulting in promising results when compared to $\mathrm{PZQ}$, the only drug currently available for the treatment of schistosomiasis ${ }^{36,37}$.

The imidazolidine derivatives used in this study, LPSF/PTS10 and LPSF/PTS23 showed no cytotoxicity up to $100 \mu \mathrm{M}$ on PBMCs. LPSF/PTS23 exhibited the best schistosomicidal properties in relation to other compounds, with $100 \%$ mortality within $24 \mathrm{~h}$, at concentrations of 20-100 $\mu \mathrm{M}$ and marked effects on motility and viability after $120 \mathrm{~h}$ at $5 \mu \mathrm{M}$. These results suggest that the efficacy varies according to the substituent in the 4-position of the imidazolidine group. The compound LPSF/PTS23 has a methoxyl group attached in the 2,4,6-position of the imidazoline ring. In a recent study it has been also shown that 

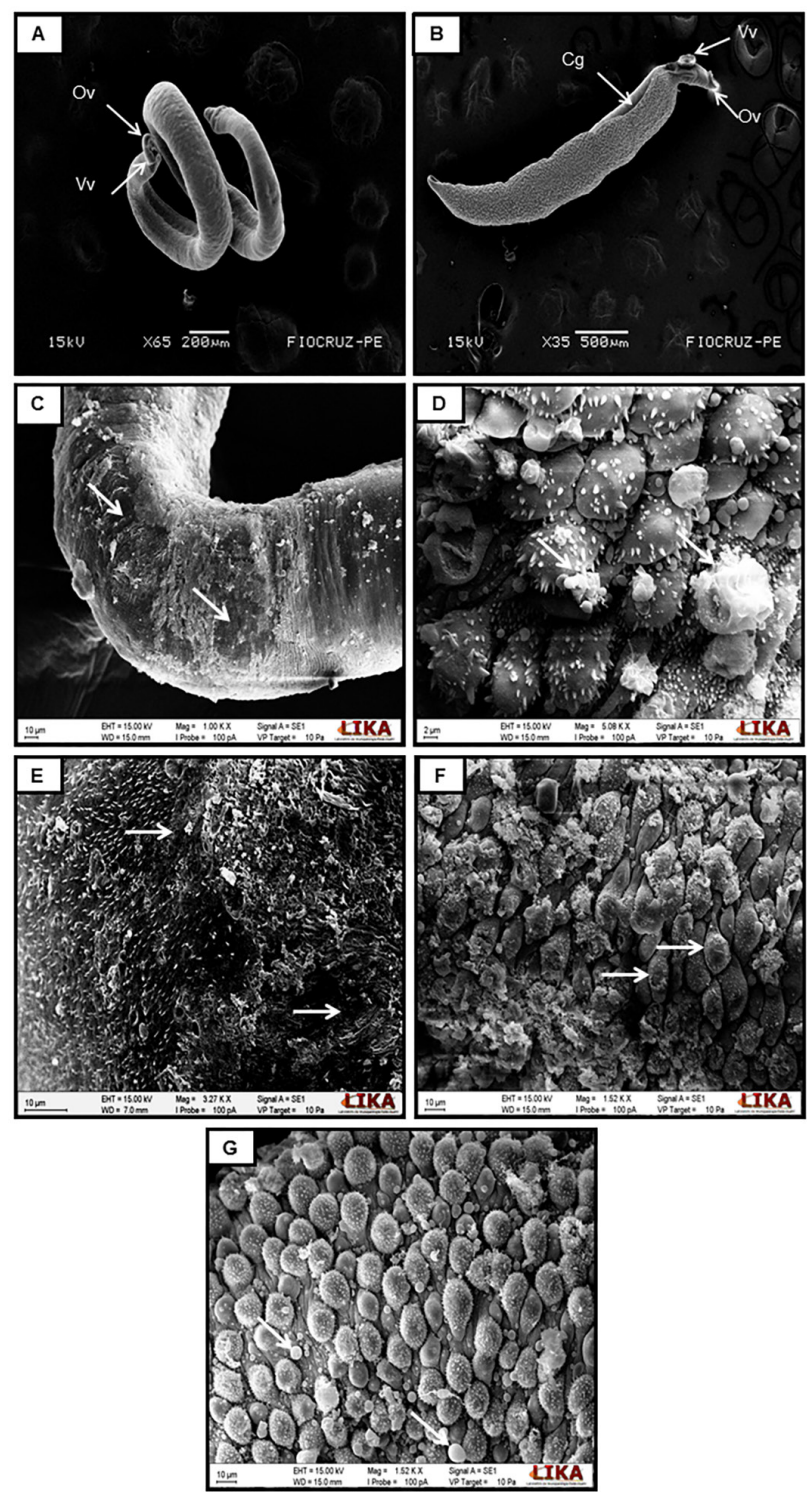

Figure 1 - a-g SEM images of adult flukes S. mansoni. (a) Adult flukes of S. mansoni not exposed to LPSF/PTS23. Parasites incubated in maintenance medium for $120 \mathrm{~h}$ showing normal morphology. (b) GC, gynecophoral channel; OS, oral sucker; VS, ventral sucker. Medial and posterior portions; (c) After $24 \mathrm{~h}$, extensive erosion was observed over the entire body of the fluke; (d) After $48 \mathrm{~h}$, multiple bubbles and projections (solid arrows) emerging from the interior of damaged tubercles; (e) After 72 $\mathrm{h}$, tegument erosion can be visualized at higher magnification; (f) After $96 \mathrm{~h}$, some tubercles lack their spines (dashed arrow. (g) Damaged tubercles and bubbles present inside the lesion, as observed after $120 \mathrm{~h}$ of drug exposition.

heterocyclic compounds (thiosemicarbazones) containing a methoxyl group exhibited higher schistosomicidal activity than compounds without this group ${ }^{38}$.

All adult worm couples were separated into individual males and females after incubation with 20,40 or $100 \mu \mathrm{M}$ of compounds LPSF/PTS10 and LPSF/PTS23. Oviposition by adult worms was also not observed at any concentration of these imidazolidines (not shown) while in the control group (untreated worms) oviposition was observed, and the worms remained viable during the entire observation period. These same physiological alterations seen here were observed in adult worms treated with imidazolidine derivatives in other studies conducted by our group (Silva et $\left.a l^{32}\right)$. For example, similar results were achieved by Neves et al. ${ }^{30}$ and Neves et al. ${ }^{31}$ using 1-(4-chlorobenzyl)4-[(4-fluorophenyl)hydrazono]-5-thioxoimidazolidin2-one (LPSF/PT11) and 5-(4-fluorobenzylidene-3-(4nitrobenzyl)-4-thioxoimidazolidin-2-one (LPSF/RSZ05).

The tegument of $S$. mansoni is an important structure involved in the absorption of nutrients, secretion of some products, variety of movements, including rapid shortening and extension of the body, typical wavy and peristaltic movement along the body axis (anterior and posterior) ${ }^{39}$. Therefore, the worm's tegument is the critical target for imidazolidine derivatives as has been shown in other studies $^{16-19}$.

To test this hypothesis, we first established the concentration of LPSF/PTS23 that is capable of altering the worm motility, causing death of worms within $120 \mathrm{~h}$ of exposure in vitro. Based on these criteria, through SEM, we observed marked changes in the surface of the tegument of $S$. mansoni adult worms including extensive erosion and the emergence of bubbles and projections ${ }^{16,17}$. Thus, we contribute, along with other studies, to the demonstration that imidazolidine derivatives induce surface membrane damage to adult worms of S. mansoni $i^{16-19}$.

However, despite their effect on the motor activity, the exact mechanisms by which LPSF/PTS10 and LPSF/PTS23 cause mortality in adult worms remain unclear.

One possible clue is provided by the fact that, some imidazolidine derivatives show toxicity to cells $\mathrm{s}^{16-19}$. There is evidence that these compounds act on cholinergic receptors ${ }^{40,41}$.

Acetylcholinesterase (AchE) and acetylcholine receptors (nAChR) are present particularly on the dorsal surface of adult male worms and have a role in nutrient uptake ${ }^{42}$. In particular, glucose uptake in vitro by Schistosoma haematobium and Schistosoma bovis adult worms is enhanced by the presence of physiological concentrations of acetylcholine. Although no such response was shown for $S$. mansoni the role of AChE and nAChR in the uptake of other nutrients cannot be ruled out ${ }^{43}$.

Silva et al. ${ }^{32}$ evaluated the schistosomicidal potential of the imidazolidine derivative 3 (5Z)-3-(4-bromobenzyl)5-(4-chlorobenzylidene)-4-thioxoimidazolidin-2-one. After 24 hours of incubation at a dose of $100 \mu \mathrm{g} \cdot \mathrm{mL}^{-1}$, adult $S$. mansoni worms had a significant opening of the gynecophoral canal, collapse of the tubercle with erosion 
of the tegument and a severe lesion revealing the layer of sub tegument tissue. In this case, there was an enormous destruction of the sub tegument surface.

Imidazolidine compounds such as (Z)-3-(4chlorobenzyl)-5-(4-nitrobenzylidene) imidazolidine-2,4dione, (Z)-3-(4-chloro-benzyl)-5-(4-fluorobenzylidene)1-methyl-2-thioxoimidazolidin-4-one and (Z)-5-(4fluorobenzilidene)-1-methyl-3-(4-phenylbenzyl)-2thioxoimidazolidin-4-one induced significant changes in the tegumental surface of the body of adult $S$. mansoni worms, causing damage in the tegument with contraction of the body and of oral and ventral suckers, disorganization and total collapse of the tubercles with loss of spines. Thus, the nitro, fluorine and phenyl radicals can justify the good activity of the imidazolidine derivatives mentioned above ${ }^{44}$.

In addition, promising results were also obtained with other imidazolidine derivatives presenting chlorine and fluorine radicals in their structure, which were also able to cause ultrastructural changes in the tegument of adult worms of $S$. mansoni, such as the derivatives 1-benzyl-4[(4-chlorophenyl)-hydrazono]-5-thioxoimidazolidin-2-one and 1-(4-chlorobenzyl)-4-[(4-fluorophenyl)-hydrazono]-5thioxoimidazolidin-2-one $\mathrm{e}^{11,16,17}$.

Furthermore, Neves et al. ${ }^{31}$ showed disruption to the tegument, blisters, spine loss and tissue wrinkling after contact with LPSF/PT5 and blisters and swelling of the tegument and loss of a few spines in the tubercules after incubation with LPSF/PT11.

Thus, in these cases the presence of nitro, fluorine and phenyl radicals could explain the high activity of the imidazolidine derivatives ${ }^{45}$ one explanation may be that halogens have the ability to enhance the absorption of the derivatives by the cell membranes ${ }^{46}$. Thus, this may be the case in the tegumental surface of the parasite treated with the above compounds as well as compounds used in the present study which all present the halogens in their chemical structures.

Our study reinforced the use of imidazoline derivatives as drug anti-S. mansoni, and identified LPSF/PTS23 as a leading candidate for further testing as a potential agent against $S$. mansoni.

\section{CONCLUSION}

In conclusion, the imidazoline derivatives which presents the trimetoxy and benzylidene halogens showed a promising in vitro schistosomicidal activity. This is the first time that the in vitro schistosomicidal activity was reported for LPSF/PTS10 and LPSF/PTS23. It is now necessary to elucidate the mechanisms of action of this compound and to evaluate its activity in vivo.

\section{ACKNOWLEDGMENTS}

Fundação de Amparo à Ciência e Tecnologia do Estado de Pernambuco (FACEPE), Instituto Nacional de Ciência e Tecnologia para Inovação Farmacêutica (INCT-if), Centro de Pesquisas Aggeu Magalhães/Fundação Oswaldo Cruz (CPqAM/FIOCRUZ/PE) and Universidade Federal de Pernambuco (UFPE).

\section{COMPETING INTERESTS}

The authors have declared that no competing interests exist.

\section{CONSENT}

The present study did not involve patients.

\section{ETHICAL APPROVAL}

All the authors hereby declare that Principles of Laboratory Animal Care (NIH publication No. 85-23, revised 1985) were followed, as well as the ethical principles of the Brazilian Society of Laboratory Animal Science (SBCAL). This project was approved by the Animal Ethics Committee from Centro de Pesquisa Aggeu Magalhães/Fundação Oswaldo Cruz (CPqAM/FIOCRUZ/ PE) and authorized by the license no. 06/2010.

\section{REFERENCES}

1. Nascimento GL, de Oliveira MR. Severe forms of schistosomiasis mansoni: epidemiologic and economic impact in Brazil, 2010. Trans R Soc Trop Med Hyg. 2014;108:29-36.

2. Vimieiro AC, Araujo N, Katz N, Kusel JR, Coelho PM. Schistogram changes after administration of antischistosomal drugs in mice at the early phase of Schistosoma mansoni infection. Mem Inst Oswaldo Cruz. 2013;108:881-6.

3. World Health Organization. Esquistosomiasis. Geneva: WHO; 2016 [cited 2016 Jul 29]. Available from: http://www.who. int/mediacentre/factsheets/fs115/es/

4. Kramer CV, Zhang F, Sinclair D, Olliaro, PL. Drugs for treating urinary schistosomiasis. Cochrane Database Syst Rev. 2013;CD000053.

5. Melman SD, Steinauer ML, Cunningham C, Kubatko LS, Mwangi IN, Wynn NB, et al. Reduced susceptibility to praziquantel among naturally occurring Kenyan isolates of Schistosoma mansoni. PloS Negl Trop Dis. 2009;3:e504.

6. Melo-Filho CC, Dantas RF, Braga RC, Neves BJ, Senger MR, Valente WC, et al. QSAR-driven discovery of novel chemical 
scaffolds active against Schistosoma mansoni. J Chem Inf Model. 2016;56:1357-72.

7. Fabri RL, Aragão DM, Florêncio JR, Pinto NC, Mattos AC, Coelho PM, et al. Chromatographic fingerprint analysis and effects of the medicinal plant species Mitracarpus frigidus on adult Schistosoma mansoni worms. Biomed Res Int. 2014;2014:941318.

8. Mourão RH, Silva TG, Soares AL, Vieira ES, Santos JN, Lima MC, et al. Synthesis and biological activity of novel acridinylidene and benzylidene thiazolidinediones. Eur J Med Chem. 2005;40:1129-33.

9. Cowan N, Yaremenko IA, Krylov IB, Terent'ev AO, Keiser $\mathrm{J}$. Elucidation of the in vitro and in vivo activities of bridged 1,2,4-trioxolanes, bridged 1,2,4,5-tetraoxanes, tricyclic monoperoxides, silyl peroxides, and hydroxylamine derivatives against Schistosoma mansoni. Bioorg Med Chem. 2015;23:5175-81.

10. Neves JK, de Lima MC, Pereira VR, de Melo CM, Peixoto CA, Pitta IR, et al. Antischistosomal action of thioxo-imidazolidine compounds: an ultrastructural and cytotoxicity study. Exp Parasitol. 2011;128:82-90.

11. Brandão SS, Andrade AM, Pereira DT, Barbosa Filho JM, Lima MC, Galdino SL, et al. A novel way of synthesis of 1,3,5-trisubstituted-2-thioxoimidazolidinones. Heterocycl Comm. 2004;10:9-14.

12. Simone CA, Zukerman-Schpector J, Pereira MA, Cuong LD, Pitta IR, Galdino SL, et al. 3-(4-Bromobenzyl)-5-(4fluorobenzylidene)-imidazolidine-2,4-dione. Acta Crystallog. 1995;C51:2620-1.

13. Caterina MC, Perillo IA, Boiani L, Pezaroglo H, Cerecetto H, González M. Imidazolidines as new anti-Trypanosoma cruzi agents: biological evaluation and structure-activity relationships. Bioorg Med Chem. 2008;16:2226-34.

14. de Carvalho GS, Dias RM, Pavan FR, Leite CQ, Silva VL, Diniz CG, et al. Synthesis, cytotoxicity, antibacterial and antileishmanial activities of imidazolidine and hexahydropyrimidine derivatives. Med Chem. 2013;9:351-9.

15. Dias LC, Dessoy MA, Silva JJ, Thiemann OH, Oliva G, Andricopulo AD, Quimioterapia da doença de Chagas: estado da arte e perspectivas no desenvolvimento de novos fármacos. Quim Nova. 2009;32:2444-57.

16. Albuquerque MC, Silva TG, Pitta MG, Silva AC, Silva PG, Malagueño E, et al. Synthesis and schistosomicidal activity of new substituted thioxo-imidazolidine compounds. Pharmazie. 2005;60:13-7.

17. Albuquerque MC, Pitta MG, Irmão JI, Peixoto CA, Malagueño E, Santana JV, et al. Tegumental alterations in adult Schistosoma mansoni treated with imidazolidine derivatives. Lat Am J Pharm. 2007;26:65-9.

18. Pitta MG, Silva AC, Neves JK, Silva PG, Irmão JI, Malagueño E, et al. New imidazolidinic bioisosters: potential candidates for antischistosomal drugs. Mem Inst Oswaldo Cruz, 2006;101 Supl 1:313-6.

19. Pitta MG, Pitta MG, Rêgo MJ, Galdino SL. The evolution of drugs on schistosoma treatment: looking to the past to improve the future. Mini Rev Med Chem. 2013;13:493-508.

20. Sudo RT, Calasans-Maia JA, Galdino SL, Lima MC, Zapata-Sudo, $\mathrm{G}$, Hernandes MZ, et al. Interaction of morphine with a new $\alpha 2$-adrenoceptor agonist in mice. J Pain. 2010;11:71-8.

21. Gouveia FL, de Oliveira RM, de Oliveira TB, da Silva IM, do Nascimento SC, Sena KX, et al. Synthesis, antimicrobial and cytotoxic activities of some 5-arylidene-4-thioxo-thiazolidine2-ones. Eur J Med Chem. 2009;44:2038-43.

22. Handzlik J, Szymanska E, Wojcik R, Dela A, Jastrzebska-Wiesek M, Karolak-Wojciechowska J, et al. Synthesis and SAR-study for novel arylpiperazine derivatives of 5-arylidenehydantoin with a1-adrenoceptor antagonistic properties. Bioorg Med Chem. 2012;20:4245-57.

23. Guarda VL, Pereira MA, De Simone CA, Albuquerque JC, Galdino SL, Chantegrel J, et al. Synthesis and structural study of arylidene thiazolidine and benzothiazine compounds. Sulfur Lett. 2003;26:17-27.

24. Karolak-Wojciechowska J, Szymanska E, Mrozek A, KiecKononowicz K. Crystallographic and spectroscopic studies of 5-arylidene-2-amino-imidazol-4-ones. J Mol Struct. 2009;930:126-34.

25. Tan SF, Ang KP, Fong YF. (Z)- and (E)-5-arylmethylenehydantoins: spectroscopic properties and configuration assignment. J Chem Soc Perkin 2. 1986;12:1941-4.

26. Rêgo MJ, Galdino-Pitta MR, Pereira DT, Silva JC, Rabello MM, Lima MC, et al. Synthesis, in vitro anticancer activity and in silico study of new disubstituted thiazolidinedione derivatives. Med Chem Res. 2014;23:3220-6.

27. Lima CM, Freitas FI, Morais LC, Cavalcanti MG, Silva LF, Padilha RJ, et al. Ultrastructural study on the morphological changes to male worms of Schistosoma mansoni after in vitro exposure to allicin. Rev Soc Bras Med Trop. 2011;44:327-30.

28. Horiuchi A, Satou T, Akao N, Koike K, Fujita K, Nikaido T. The effect of free and polyethylene glycol-liposome-entrapped albendazole on larval mobility and number in Toxocara canis infected mice. Vet Parasitol. 2005;129:83-7.

29. Matos-Rocha TJ, Cavalcanti MG, Barbosa-Filho JM, Lúcio AS, Veras DL, Feitosa AP, et al. In vitro evaluation of schistosomicidal activity of essential oil of Mentha $\mathrm{x}$ villosa and some of its chemical constituents in adult worms of Schistosoma mansoni. Planta Med. 2013;79:1307-12.

30. Neves JK, Sarinho S, Melo CM, Pereira VR, Lima MC, Pitta IR, et al. Immunological studies and in vitro schistosomicide action of new imidazolidine derivatives. J Venom Anim Toxins Incl Trop Dis. 2011;17:277-86.

31. Neves JK, Botelho SP, Melo CM, Pereira VR, Lima MC, Pitta IR, et al. Biological and immunological activity of new 
imidazolidines against adult worms of Schistosoma mansoni. Parasitol Res. 2010;107:531-8.

32. Silva AL, Oliveira SA, Oliveira JF, Santiago EF, Almeida Júnior AS, Jacobi IT, et al. Tegumental changes in adult Schistosoma mansoni induced by a new imidazolidinic derivative. Brit $\mathrm{J}$ Pharm Res. 2014;4:1988-2005.

33. Cowan N, Keiser J. Repurposing of anticancer drugs: in vitro and in vivo activities against Schistosoma mansoni. Parasit Vectors. 2015;8:417.

34. Heimburg T, Chakrabarti A, Lancelot J, Marek M, Melesina J, Hauser AT, et al. Structure-based design and synthesis of movel inhibitors targeting HDAC8 from Schistosoma mansoni for the treatment of schistosomiasis. J Med Chem. 2016;59:2423-35.

35. Dubois F, Caby S, Oger F, Cosseau C, Capron M, Grunau C, et al. Histone deacetylase inhibitors induce apoptosis, histone hyperacetylation and up-regulation of gene transcription in Schistosoma mansoni. Mol Biochem Parasitol. 2009;168:7-15.

36. Pica-Mattoccia L, Cioli D. Sex- and stage-related sensitivity of Schistosoma mansoni to in vivo and in vitro praziquantel treatment. Int J Parasitol. 2004;34:527-33.

37. Silva AL, Oliveira JF, Silva WL, Luis AF, Santiago EF, Almeida Júnior AS, et al. In vivo study of schistosomicidal action of 1-benzyl-4-[(4-fluoro-phenyl)-hydrazono]-5-thioxoimidazolidin-2-one. Biomed Pharmacother. 2016;83:502-7.

38. Santiago EF, Oliveira SA, Oliveira Filho GB, Moreira DR, Gomes PA, Silva AL, et al. Evaluation of the anti-Schistosoma mansoni activity of thiosemicarbazones and thiazoles. Antimicrob Agents Chemother. 2014;58:352-63.
39. Taman A, Ribeiro P. Glutamate-mediated signaling in Schistosoma mansoni: a novel glutamate receptor is expressed in neurons and the female reproductive tract. Mol Biochem Parasitol. 2011;176:42-50.

40. Tallima H, El Ridi R. Praziquantel binds Schistosoma mansoni adult worm actin. Int J Antimicrob Agents. 2007;29:570-5.

41. Thibaut JP, Monteiro LM, Leite LC, Menezes CM, Lima LM, Noel F. The effects of 3-methylclonazepam on Schistosoma mansoni musculature are not mediated by benzodiazepine receptors. Eur J Pharmacol. 2009; 606:9-16.

42. Camacho M, Agnew A. Schistosoma: rate of glucose import is altered by acetylcholine interaction with tegumental acetylcholine receptors and acetylcholinesterase. Exp Parasitol. 1995;81:584-91.

43. Noel F. Sistema neuromuscular e controle da motilidade do verme adulto. In: Carvalho OS, Coelho PM, Lenzi HL, organizadores. Schistosoma mansoni \& esquistossomose: uma visão interdisciplinar. Rio de Janeiro: Fiocruz; 2008. p.207-44.

44. Paulai FR, Serrano SH, Tavares LC. Aspectos mecanísticos da bioatividade e toxicidade de nitrocompostos. Quim Nova. 2009;32:1013-20.

45. Oliveira SM, Albuquerque MC, Pitta MG, Malagueño E, Santana JV, Lima MC, et al. A resposta do Schistosoma mansoni mantido in vitro frente a derivados imidazolidinônicos. Acta Farm Bonaerense. 2004;3:343-8.

46. Thomas G. Química medicinal: uma introdução. Rio de Janeiro: Guanabara Koogan; 2003. 